http://dx.doi.org/10.18675/1981-8106.vol26.n51.p49-63

\title{
Currículo e Prática Pedagógica em uma Escola do Campo no Interior da Bahia
}

\author{
Curriculum and Pedagogical Practice in a Rural School within the Bahia
}

Currículo y Práctica Pedagógica en una Escuela Rural en Bahia

\author{
Benedito G. Eugênio' \\ Roseli Inocêncio Santos" \\ 'Universidade Estadual do Sudoeste da Bahia (UESB), Bahia - Brasil. E-mail: \\ beneditoeugenio@bol.com.br \\ " Universidade Estadual do Sudoeste da Bahia (UESB), Bahia - Brasil. E-mail: \\ rosesantos_18@hotmail.com
}

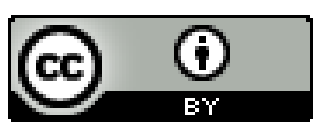

Educação: teoria e prática, Rio Claro, SP, Brasil - eISSN: 1981-8106

Está licenciada sob Licença Creative Common

\section{Resumo}

O texto apresenta os resultados de uma pesquisa que buscou compreender como se configura o desenvolvimento do currículo no cotidiano da sala de aula de uma escola do campo a partir da prática pedagógica de uma professora. A perspectiva de análise é a teoria crítica de currículo a partir da teoria sociológica de Basil Bernstein (1996). São discutidos no texto alguns dos elementos presentes na teoria bernsteiniana que nos auxiliam no entendimento da prática pedagógica, tais como as regras do discurso pedagógico. Para isso, foram realizadas observações e entrevistas com uma docente que trabalha em uma escola do campo, localizada na zona rural de Vitória da Conquista-BA. O artigo está assim organizado: inicialmente é situado o local da pesquisa; na sequência, pontua-se acerca da importância dos estudos que procuram compreender o cotidiano da sala de aula e, finalmente, são analisados os dados construídos na pesquisa. As conclusões assinalam para indícios de uma prática pedagógica mista, prática que propicia a aquisição das regras de reconhecimento e de realização, as quais, por sua vez, possibilitam a produção do texto escolar esperado pelo professor para os alunos desfavorecidos socialmente, como no caso da docente pesquisada e presente no currículo em 
ação.

Palavras-chave: Currículo; Educação do Campo; Prática Pedagógica.

\begin{abstract}
The paper presents the results of a study that sought to understand the configuration of the curriculum's development in a classroom of a rural school from the pedagogical practice of a teacher. The perspective of analysis is the sociological theory of Basil Bernstein. Discussed some of the elements present in Bernstein's theory that help us understand the pedagogical practice, such as the rules of the pedagogical discourse. The instruments were observations and interviews conducted with a teacher working in a rural school located in the rural area of Vitoria da Conquista, Bahia. The paper is organized as follows: situated place of study; the importance of studies that seek to understand the classroom work, and data analysis. The findings indicate evidence for a mixed pedagogical practice, which allows for acquisition of recognition and realization rules, which, in turn, enable the production of school text expected by the teacher, to socially disadvantaged pupils in the case of teacher investigated and present in the curriculum in action.
\end{abstract}

Keywords: Curriculum; Rural Education; Teaching Practice.

\title{
Resumen
}

El artículo presenta los resultados de un estudio que trató de entender la configuración del desarrollo del currículo en el cotidiano de un aula de clases de una escuela en el campo, desde la práctica pedagógica de una profesora. La perspectiva de análisis es la teoría crítica sociológica de Basil Bernstein (1996). Se discute algunos de los elementos presentes en la teoría bernsteiniana que ayudan a entender la práctica pedagógica, tales como las reglas del discurso pedagógico. Para ello, las observaciones y las entrevistas se realizaron con una maestra que trabaja en una escuela en el campo, ubicada en Vitoria da Conquista, Bahia. El artículo se organiza de la siguiente manera: primero se sitúa el local de la investigación; en secuencia, se puntua sobre los estudios que tratan de entender el cotidiano del aula declases y, finalmente, se analizan los datos de la pesquisa. Las conclusiones indican una evidencia de una práctica pedagógica mixta, práctica que permite la adquisición de reglas de reconocimiento y de realización reglas, las cuales, a su vez, permiten la producción del texto escolar esperado por el profesor de los alumnos socialmente desfavorecidos, como en el caso de la maestra pesquisada y presente en el currículo en acción.

Palabras clave: Plan de Estudios; Escuela Rural; Práctica Pedagógica. 


\section{Introdução}

Este artigo apresenta os resultados de uma pesquisa que buscou compreender como se configura o desenvolvimento do currículo no cotidiano da sala de aula de uma escola do campo a partir da prática pedagógica de uma professora. A perspectiva de análise é a teoria crítica de currículo, mesmo cientes das críticas direcionadas a essa linha de estudos do currículo, tais como as elencadas por Negri (2010).

A teoria crítica de currículo, valendo-se de um olhar sociológico para esse artefato, inicia-se nos anos 1970, com a Nova Sociologia da Educação (NSE) e o Movimento de Reconceituação, que propunham, desde diferentes perspectivas teórico-metodológicas marxista, humanista, fenomenológica -, uma análise crítica dos saberes escolares selecionados para serem trabalhados na escola. Data desse período a preocupação com as questões culturais do currículo, com as desigualdades educacionais e com os pressupostos de classe social presentes no processo de seleção dos conhecimentos a serem ensinados.

As análises dos autores da NSE seriam ampliadas posteriormente, nos anos 1980, com os trabalhos de Apple e Giroux, autores que se voltaram para a análise da relação entre currículo e estrutura social, ideologia, hegemonia, cultura, relações de poder, ajudando-nos a compreender que o "currículo não é um elemento inocente e neutro de transmissão desinteressada do conhecimento [...] O currículo não é um elemento transcendental e atemporal - ele tem uma história vinculada a formas específicas e contingentes de organização da sociedade e da educação"(MOREIRA E SILVA, 1999, p.08). Hoje é fundamental que as análises críticas do currículo incorporem também as questões de raça/etnia, diversidade cultural, gênero e sexualidades, a fim de que a chamada justiça curricular seja possível.

Uma possibilidade de entendimento do trabalho curricular no interior das práticas pedagógicas é a análise do currículo em ação (por alguns denominada de praticado, currículo cotidiano). $\mathrm{O}$ currículo em ação é aqui compreendido tal como proposto por Geraldi,“conjunto das aprendizagens vivenciadas pelos alunos, planejadas ou não pela escola, dentro ou fora da aula ou da escola, mas sob a responsabilidade desta ao longo de sua trajetória escolar" (1994, p.117).

Em nossa pesquisa, para a obtenção dos dados, realizamos entrevistas com uma professora do $5^{\circ}$ ano do ensino fundamental, observamos 7 aulas dessa docente, em uma escola pública localizada no povoado da Gameleira, município de Vitória da Conquista.

Para a execução de nosso trabalho, valemo-nos do conceito de prática pedagógica de Bernstein: "contexto social fundamental através do qual se realiza a reprodução e a produção culturais" (1998, p.35). Para a compreensão da prática pedagógica é fundamental analisar as questões relacionadas a poder e controle, tendo em vista que "as relações de poder criam, justificam e reproduzem as fronteiras entre diferentes categorias: raça, classe social, gênero, discurso, de agentes e de espaço" ( PICCOLI, 2009, p.31). 
A prática pedagógica possui uma lógica interna e é constituída por um conjunto de três regras: hierárquicas, de sequenciamento e criteriais. Elas atuam seletivamente sobre o conteúdo. A regra hierárquica é a dominante e estabelece as condições para a ordem, o caráter e os modos de comportamento. Os papéis de transmissor e adquirente são muito bem definidos, criando as condições para as condutas desejadas para cada um na relação pedagógica.

As regras de sequenciamento definem a progressão da transmissão, ou seja, o que vem antes e o que vem depois, regulando o ordenamento temporal do conteúdo. Para Bernstein, "se existe uma progressão, deve haver regras de sequenciamento" (1996, p.97). Essas regras implicam regras de compossamento, ou seja, o tempo permitido para se cumprir as regras de sequenciamento.

As regras de compossamento definem a velocidade esperada para que a aprendizagem ocorra e podem ser explícitas ou implícitas. No primeiro caso, elas regulam o desenvolvimento da criança em termos de idade, construindo o projeto temporal da criança e, no segundo, as crianças pode não ter jamais conhecimento de seu projeto temporal, pois ele é de conhecimento apenas do transmissor. As regras de sequenciamento podem estar inscritas em listagens de conteúdos, em currículos, em regras de comportamento, em regras de prêmios e em castigo.

As regras criteriais consistem em avaliar a competência do adquirente, isto é, "se os critérios que se tornaram disponíveis para o adquirente foram alcançados" (BERNSTEIN, 1996, p.98). Essa avaliação baseia-se nas condutas, no caráter, nos modos de comportamento (critérios regulativos) ou na resolução de um problema ou na produção de um segmento de escrita/fala (critério instrucional/discursivo).

O artigo está assim organizado: inicialmente situamos o local da pesquisa; na sequência, pontuamos acerca da importância dos estudos que procuram compreender o cotidiano da sala de aula e, finalmente, analisamos os dados construídos na pesquisa.

\section{Situando o Local da Investigação}

O povoado da Gameleira fica localizado a $18 \mathrm{~km}$ da cidade de Vitória da Conquista; é um povoado pequeno, possui apenas uma escola que atende aos alunos dos anos iniciais do ensino fundamental. Ao pesquisar sobre o surgimento da escola, fomos informados de que a comunidade lutou por um espaço mais adequado para o funcionamento da escola. Essa luta avançou com alguns políticos da região e, assim,surgiu a autorização do prefeito municipal Fernando Spínola (1967-1971) para a construção da escola nesse povoado.

A escola foi inaugurada no começo dos anos 1970 num clima de muita festa e com a presença do prefeito Fernando Spínola. A instituição possui apenas o segmento que compreende os anos inicias, assim que, ao término deles, os discentes têm que se deslocar 
para o povoado do Pradoso, no turno vespertino, para a continuidade de sua escolarização. Urge ressaltar que o transporte é disponibilizado pela Secretaria Municipal da Educação.

No povoado, as pessoas vivem economicamente de várias maneiras; os mais idosos são aposentados, e os mais jovens sustentam a família trabalhando em roças da própria localidade ou de povoados vizinhos, outros vivem da plantação de hortaliças. Como o grau de parentesco sempre é muito próximo, fica fácil trabalhar um grande número de pessoas com hortas, outros saem para trabalhar na cidade com serviços variados, algumas mulheres saem para trabalhar como empregada doméstica na cidade. A maioria da população trabalha nas roças de café, cultura típica da região. No período de sua colheita, inclusive, é muito comum as crianças deixarem a escola. A cultura da localidade ainda é preservada principalmente pelos mais velhos como, por exemplo, as rezas, o caruru (reza oferecida aos santos Cosme e Damião), festa da igreja católica com a prática da procissão e o andor, as festas de São João e os ternos de reis no mês de janeiro.

\section{Algumas Considerações sobre a Pesquisa com o Cotidiano Escolar}

O estudo do cotidiano vem sendo efetuado no Brasil por diferentes pesquisadores, principalmente a partir dos anos 1980. Num primeiro momento, os estudos tomavam como base os escritos de Agnes Heller. Posteriormente, Certeau (ano) passou a ser uma referência importante nas investigações.

Segundo André (2008), para conhecer a realidade da escola é preciso ajustar o olhar para as interações e relações que se passa no seu dia a dia observando, assim, as forças que a controlam, as forças de poder, como se organiza o trabalho pedagógico, o papel de cada pessoa inserida nesse contexto, que por sua vez produz, reproduz e modifica as ações e relações no âmbito escolar. Sendo assim, a partir do momento em que vemos a escola em constante movimento e como espaço em que se produz e se reproduz conhecimentos, valores e significados não é mais válido a forma estática de ver o cotidiano.

André (2008) aponta quatro aspectos necessários para investigar a prática pedagógica no cotidiano escolar, sendo eles “a) subjetivo/pessoal, b) institucional/organizacional, c)institucional/relacional d) sociopolítico, um é interligado ao outro.

A dimensão subjetiva é a história de cada pessoa, suaa forma de agir, sua forma de se posicionar, de se comunicar e de se alienar em meio a sua socialização cotidiana.

O estudo da dimensão subjetiva vai requerer um contato com os sujeitos, em situações formais ou informais de entrevistas -individuais ou coletivas de modo que lhe permita expressar opiniões, ponto de vistas, concepções e representações (ANDRÉ, 2008, p.143). 
A dimensão institucional ou institucional se refere ao contexto da prática escolar, tratase da forma em que o trabalho está organizado, as formas de poder e de decisão existentes, a participação de cada pessoa e dos recursos, sejam eles humanos ou materiais. Segundo André (2008), nessa dimensão o contexto social pode interferir no contexto escolar por meio dos pais e comunidades, os valores e a cultura de cada sujeito e as políticas educacionais.

Ainda de acordo com André (2008), o estudo dessa dimensão exige contato direto com todo o pessoal da escola, o uso de entrevistas individuais ou coletivas ou conversas informais, acompanhamento em reuniões, atividades e análises de documentos importantes para o funcionamento da escola.

A dimensão institucional ou pedagógica se refere aos momentos em que acontece a relação entre professor-aluno-conhecimento, por meio dos objetivos e conteúdos, das atividades e dos materiais didáticos, e dos meios de comunicação entre professor-aluno e, também a forma de avaliação do ensino-aprendizagem.

O encontro professor-aluno-conhecimento se define, por um lado, pela apropriação ativa do conhecimento por parte do aluno, pela mediação exercida pelo professor e, por outro, por todo um processo de interação em que entram componentes afetivos, morais, políticos, éticos, cognitivos, sociais, etc. (ANDRÉ, 2008, p.143).

A autora aponta que é preciso levar em consideração a realidade do aluno em seus diversos aspectos, sejam cognitivos ou econômicos e a realidade do professor, seja em relação ao trabalho ou à vida pessoal e sua ligação com a escola em suas diversas relações intra ou extraescolar; é preciso levar em consideração também os conteúdos e as formas de trabalho para, enfim, compreender como a escola educa e socializa. Dessa forma, conforme André (2008), para que ocorra a investigação, é preciso utilizar a observação do processo de ensinoaprendizagem e a análise do material utilizado pelo professor e produzido pelo aluno.

A outra dimensão é a sociopolítica, que se refere às políticas educacionais que interferem no cotidiano escolar e às mudanças que acontecem na sociedade, nas mídias e nas relações e interfere nos sentimentos, nos valores e nas emoções de todas as pessoas da escola.

De acordo com André (2008), para investigar o cotidiano escolar é preciso levar em consideração essas quatro dimensões, visto que ele é muito amplo e dinâmico, o que exige muita atenção do pesquisador.

Essas dimensões estão presentes neste trabalho, pois para a realização da pesquisa foi necessário conhecer a história da professora, bem como sua forma de agir e se posicionar frente aos alunos, logo, utilizamos a dimensão subjetiva para poder realizar a entrevista. Utilizamos também a dimensão institucional para saber o papel de cada pessoa inserida no contexto escolar e os recursos de que a escola dispõe. A dimensão pedagógica pôde ser 
observada ao presenciar a interação professor-aluno-conhecimento e, a dimensão sociopolítica foi empregada para entender as políticas e mudanças sociais que interferem na escola. Por conta do espaço do artigo, essas dimensões não serão detalhadas.

\title{
4 No Interior da Sala de Aula: a Prática Pedagógica no Currículo em Ação
}

Apresentamos, a seguir, o processo de configuração do currículo em ação no interior da sala de aula. As observações do cotidiano da sala de aula possibilitaram identificar que a professora mantém uma boa relação com a turma e os alunos também mantém uma boa relação com ela. Presenciamos momentos de descontração, inclusive quando os alunos se reportavam ao que viam na televisão. Os discentes também ajudavam a docente, pediam sempre para apagar o quadro. Presenciamos também situações em que a turma se dispersava e era preciso a professora intervir.

Em um dos dias da observação, a professora trabalhou conteúdo referente à pátria, conforme Diário de Campo:

\begin{abstract}
Com a sala em círculo, a professora colocou a sua cadeira no centro da sala e questionou os alunos quanto às suas visões em relação ao Brasil que tínhamos, ao Brasil que temos e ao Brasil que queremos. Depois de questioná-los, ela dividiu a sala em três grupos de acordo com as três categorias elencadas (O Brasil que tínhamos, o que temos e o que queremos) e pediu para que eles confeccionassem um. Ela os deixou livres para usar os recursos; então eles cortaram o papel madeira e fizeram o cartaz. A professora só entregou dois desenhos prontos para cada cartaz, depois pediu que eles fizessem frases e preparassem uma apresentação para a próxima aula.
\end{abstract}

No outro dia, antes das apresentações, a professora retoma a conversa com eles e passa a provocar reflexões nos alunos:

Professora $(\mathrm{P})$-E em relação à educação, por que hoje tem mais oportunidade de estudar e melhores recursos que antes, e os alunos não aprendem e nem se interessam?

Alunos (A) - Antes os alunos respeitavam mais.

P - Antigamente as mulheres não podiam estudar, pois os pais achavam que elas iam escrever carta para namorado.

A- As mulheres não tinham direito a trabalhar e nem a carteira assinada.

P- E isso é bom ou ruim? 
A-É ruim, pois as mulheres hoje vão trabalhar e trai os homens.

P-E você acha que é isso que faz as mulheres traírem e as que ficam em casa e traem assim mesmo? Antes os homens davam tudo às mulheres e elas não sentiam necessidade de trabalhar.

A - Os direitos são iguais.

A- O homem fica mais tarde na rua.

P- Ficar mais tarde na rua, beber e fumar não é bom nem pro homem nem para a mulher (Diário de Campo).

Nessa cena de aula, verificamos a presença da regra regulativa. É o discurso que se preocupa com a transmissão das regras de ordem social. Mesmo trabalhando com o currículo de coleção, havia uma fraca classificação entre os conteúdos. O enquadramento, isto é, "a natureza do controle que se exerce sobre a seleção da comunicação, a sequenciação, a ritmagem, os critérios do conhecimento e o controle da base social que torna possível essa transmissão" (BERNSTEIN, 1998, p.44), também era fraco, pois os conhecimentos escolares eram valorizados, mas a professora relacionava-os com conteúdos não-escolares trazidos por ela e pelos alunos.

Outros indícios do que abordamos acima são: a linguagem, muitas vezes coloquial, empregada pela professora para estimular a participação dos estudantes; as conversas, muitas delas informais, com os alunos.

No outro dia os grupos apresentaram; apenas um grupo (o Brasil que tínhamos) se organizou, confeccionou um chapéu e uma espada no PETI (Programa de Erradicação do Trabalho Infantil) pela manhã para apresentar à tarde; os outros grupos apenas leram o cartaz.

A professora chamou a atenção dos outros grupos, falou que se eles precisassem de tempo que era só eles pedirem que ela dava, para eles se organizarem. Também chamou a atenção dos alunos para o significado da palavra grupo.

A docente questionou para a turma se somos realmente independentes e falou que temos coisas boas e ruins e também citou o que os alunos haviam falado de político corrupto (Diário de Campo).

P - Os políticos querem estudantes críticos?

A - Não.

P - A escola deve formar cidadãos críticos que tenham coragem para reclamar seus direitos cientes de seus deveres.

A - Respeitar os idosos inclusive nos transportes. 
A professora usa o exemplo da localidade.

$\mathrm{P}$ - Na zona urbana os idosos fazem a carteirinha e não pagam o transporte coletivo, aqui na zona rural os idosos pagam o e tanto aqui quanto na zona rural alguns jovens não levantam para dar lugar aos idosos.

A() - Minha mãe manda eu levantar mas eu também pago.

P - Mas os idosos já estão com as pernas cansadas, precisamos dar os lugares tanto para les quanto para as mulheres grávidas e os deficientes, temos que respeitar, ter solidariedade e humildade.

A (c) - Deveria ter carro só para os idosos (Diário de Campo).

Interessa-nos aqui não o conteúdo em si trabalhado na aula, mas o que e o como da prática pedagógica, pois, segundo Bernstein, qualquer relação pedagógica compõe-se de transmissores e adquirentes. Os sujeitos envolvidos nesse processo aprendem a ser transmissor ou adquirente, tendo em vista que este processo implica na "aquisição de regras de ordem social, de caráter e de modos de comportamento que se tornam a conduta apropriada para a relação pedagógica" (1996, p.96).

As regras de compossamento não eram rígidas. Ritmo (no caso do aluno) e ritmagem (taxa de aprendizagem que o professor planeja conseguir num determinado limite de tempo) e, como elementos da regra instrucional, ditavam o sequenciamento da prática pedagógica, isto é, o que deve vir antes e o que deve vir depois.

Nos dias seguintes, a professora deu prosseguimento à matemática, passou um texto no quadro e dele extraiu as questões, trabalhou a divisão, segundo ela, o assunto têm mais dificuldade. A docente disse que o livro que ela estava utilizando era da coleção Planeta Azul. Após passar o texto na lousa, a professora falou para a turma que ele era de matemática, mas que eles poderiam observar os sinais de pontuação. Ela trabalhou também com atividades de Língua Portuguesa, relembrando o sinônimo e o antônimo.

A - O antônimo é mais fácil (e responde a tarefa)

- Começar terminar

P - E vocês podem falar assim para todos.

A professora percebeu que alguns alunos estavam olhando para as respostas do colega e então chama a atenção da seguinte forma.

$\mathrm{P}$ - Esse assunto já foi dado várias vezes, e alunos de $4^{\mathrm{a}}$ série precisar olhar para o do colega para responder, vocês não pegam livros, não diz que tem dicionário em casa e no entanto não tem curiosidade de ler?

Se quiserem ser alunos informados têm que gostar de ler. Vários sociólogos falam da idade da descoberta e vocês estão nela, que mente vazia é esta? 
Antes não tinha recursos nas escolas, não tinha TV, no entanto, os alunos eram mais interessados que vocês. (REFERÊNCIA Diário de Campo)

Na relação professor e aluno, segundo Bernstein (1996), a interação é expressa através do poder (classificação) e do controle (enquadramento). A classificação se refere às relações entre os conteúdos, tendo em vista que em suas práticas os docentes podem estabelecer ou não relação entre os conteúdos e isso definirá o grau de classificação (forte ou fraco) entre eles.

No caso aqui analisado, verificamos um enquadramento fraco, caso em que o adquirente, pelo menos aparentemente, tem controle sobre a comunicação, tendo em vista que na entrevista, a professora afirmou perceber "[...] que o aluno não se interessa nem mesmo quando se usa questões do seu cotidiano", acrescentando ainda "[...] que é preciso encontrar um meio de trazer conteúdos, trabalhos para serem feitos em sala de aula que façam com que o aluno tenha vontade de estudar."A professora enfatiza que valoriza os conhecimentos que os alunos trazem "[...] questionando e pedindo eles para trazer alguma coisa de casa para confeccionar e que isso enriquece bastante é dá continuidade ao trabalho".

Sacristán (2000) aponta que a mediação do professor é muito importante para a aprendizagem dos alunos, principalmente quando o conteúdo trabalhado inclui o aluno ou quando é dada autonomia e ação aos alunos por meio de atividades como saídas da escola, pesquisas de tarefas para serem feitas em casa e o uso de outros materiais.

No período de observação foi possível perceber que a professora e os alunos mantinham uma boa relação. Ela prima pelo diálogo na hora de transmitir o conteúdo. Em um dos momentos de observação, quando estava dialogando com eles a respeito do conteúdo, os alunos começaram a conversar e ela explicou que aula não é só escrever e ler: "[...] acredito que talvez eles já tenha se costumado com o ritmo de aula tradicional”.

No período das observações ela nos informou que estava trabalhando o conteúdo pátria. Disse-nos também que estava com um miniprojeto sobre desenvolvimento sustentável para trabalhar no mês de setembro.

A professora ressaltou que para aquele dia tinha planejado a confecção de
cartaz, perguntando aos aluno o que eles entendiam por pátria e permitindo
que eles colocassem suassobre o Brasil que temos, o Brasil que tínhamos e o
que eles querem para o um Brasil diferente do que está hoje, ou seja, o Brasil
que queremos. A partir da opinião das opiniões provocou reflexões neles
sobre diversas questões, questionando-os sobre a situação da saúde e da
educação no Brasil que temos e usou como exemplo o caso da funcionária
que precisa operar e tem que esperar meses. Fala ainda da responsabilidade
de saber votar no candidato certo para tentar resolver a situação e cita o caso
de uma cidade vizinha onde o prefeito e a mulher são corruptos Diário de
Campo). 
De acordo com Morais et al (1993), diferentes formas de distribuição de classificação e enquadramento moldam as práticas pedagógicas, regulando a consciência e a identidade de professores e alunos. Discurso regulador (regras de ordem social) e discurso instrucional (regras de ordem discursiva) compõem o discurso pedagógico. $\mathrm{Na}$ cena a seguir destacamos como esses dois discursos se apresentam na prática pedagógica.
Alunos - Igual à novela.
A professora usa o exemplo dado pelos alunos para falar sobre a televisão.
P- Na televisão vemos coisas boas e ruins.
P- Eu gosto do Pica pau, mas vocês já perceberam o quanto que ele é maldoso? Dessa forma, assisto só para passar o tempo e não para aprender. (REFERÊNCIA)

Ainda de acordo com a entrevista realizada, existem conteúdos que ela sente necessidade de dar mais atenção, que são os conteúdos de português e matemática, pois "[...] nessas duas disciplinas os alunos sentem mais dificuldade". Ela disse que se esforça para ver qual a melhor forma para passar o conteúdo; para isso usa gravura, música e filme, porque com esses recursos os alunos conseguem aprender mais e também gostam.

Tomando as dimensões da prática pedagógica propostas por Morais et al (1993), temos que os discursos instrucional e regulador que compõem o currículo podem ser assim esquematizados: C-, E-, no que se refere às categorias conteúdo escolar/conteúdo não escolar; conteúdos da disciplina/conteúdos de outras disciplinas. Quanto ao discurso instrucional específico observado a partir das categorias do enquadramento, temos: seleção E+, sequência E-, ritmagem E-, avaliação $\mathrm{E}+{ }^{1}$.

No que diz respeito à avaliação, a Proposta de Educação do Campo da Rede Municipal de Ensino aponta que essa deve ser diagnóstica e contínua, ao invés de exames que classificam o aluno em bons e ruins. Nesse sentido, a professora expressa como realiza seu processo de avaliação:

A minha avaliação aqui é processual, a cada dia eu estou avaliando e eu ainda uso aquela avaliação de fazer tipo uma provinha da maneira mais fácil, não falando também para o aluno que é realmente uma prova, porque isso $[\ldots]$

Aí trava mesmo para ele e, às vezes, a gente tá aqui trabalhando uma atividade, aí eu vou aqui, eu passo uma atividade, às vezes objetiva, às vezes subjetiva e aí eu já coloco como avaliação.

\footnotetext{
${ }^{1}$ Morais et al apresenta a seguinte observação quanto ao enquadramento: E++ (muito forte), E+ (forte), E(fraco), E- - (muito fraco), E- - - (fraquíssimo). 
Observamos aqui uma confusão entre avaliação e medida; mas verificamos também a tentativa de uma avaliação qualitativa, ou seja, preocupada com a garantia da aprendizagem. No entanto, conforme Cabrera,

[...] é importante ressaltar que uma avaliação com esse caráter, por si só, não garante que práticas progressistas e libertadoras estejam sendo instaladas e que a visão conservadora de educação seja substituída (2007, p.35).

De acordo com Bernstein (1996), a avaliação, como elemento das regras criteriais, funciona com base em dois tipos de critérios: os reguladores (condutas, caráter, modos de comportamento) e os instrucionais (aquisição de conhecimentos e habilidades). No caso da docente investigada, as regras criteriais eram implícitas, o que pode nos dar indícios de uma pedagogia invisível.

Perguntada sobre os materiais didáticos que a escola recebe, se esses são adequados às condições da região, a professora informou que dispõe de poucos materiais e que conta com o livro didático, mesmo ele não sendo propriamente para a escola do campo. O livro didático funciona, para a docente investigada, como um recurso que se apresenta para ensinar como superior a qualquer outro recurso didático, isto é, há um "processo de naturalização desse tipo determinado de material curricular, pressupondo que uma prática educacional é adequada à medida que tem o material curricular presente de um modo relevante" (BONAFÉ E RODRÍGUEZ, 2013, p.217).

O livro didático, segundo Bonafé e Rodríguez "é o artefato que dá forma material a um modo de proceder pedagógico para a reprodução cultural. O currículo se torna texto e sua materialização coloniza a vida na aula" (2013, p.209),. Estes autores efetuaram uma revisão dos estudos sobre o livro didático na Espanha e alguns países da América Latina. A partir disso, elaboraram as principais linhas de pesquisas acerca da temática. Destacamos aqui, dentre outros: a) estudos sobre o papel e a influência nas práticas de aulas dos livros didáticos e materiais curriculares e os processos de seleção dos mesmos; b) os discursos ideológicos por trás dos materiais; c) aspectos formais (ilustrações) nos livros didáticos e materiais curriculares; d) o livro didático como discurso curricular e de profissionalismo docente; e) processos de comercialização do livro didático.

Esse artefato possui papel importante na prática pedagógica, sendo empregado cotidianamente na sala de aula investigada, mas com uma característica fundamental: o processo de recontextualização, que de acordo com Bernstein (1996), dá-se em dois campos, quais sejam, o recontextualizador oficial (CRO) e o recontextualizador pedagógico (CRP). É no CRP que os agentes constroem os textos e as práticas pedagógicas. No caso da docente em pesquisa, a autonomia se fazia presente no CRP.

Se, como diz Acosta, "os saberes ensinados são uma mescla de tradição e inovação 
pedagógica" (2013, p.188), podemos afirmar que na prática pedagógica da docente investigada esse elemento se fez presente, tendo em vista que por mais que o livro fosse um artefato sempre utilizado, ele se mesclava com as questões do cotidiano.

A professora informou que tenta sempre trazer novidades para seus alunos, referentes não só à escola rural, mas também da urbana, pois entende que o aluno precisa desse intercâmbio entre cidade e campo para ampliar seus conhecimentos.

Sacristán (2000) enfatiza o papel importante que tem o professor como um construtor do currículo na prática e na transmissão dos conteúdos na escola, na escolha de métodos, técnicas e meios, visto que sua profissão não lhe permite agir de forma puramente técnica e, apesar das imposições e controle, a prática cotidiana lhe dá brecha para modificar aspectos e conteúdos curriculares até mesmo pensando em atender às dificuldades dos alunos.

Quanto aos recursos naturais presentes na comunidade, a professora enfatiza que usa o que a comunidade tem mesmo, as árvores, a questão do solo, para trabalhar principalmente os conteúdos relacionados a ciências. Aponta também a adoção desses elementos como positiva para o trabalho com os conteúdos curriculares.

As discussões aqui apresentadas apontam, no caso da docente investigada, para indícios de uma prática pedagógica mista. Segundo Morais (2002) e Morais e Neves (2003), essa prática propicia a aquisição das regras de reconhecimento e de realização, que, por sua vez, possibilitam a produção do texto escolar esperado pelo professor para os alunos desfavorecidos socialmente.

Concluímos, destacando as potencialidades da teoria sociológica bernsteiniana para a compreensão dos macros e microprocessos educacionais, que sua teoria, ao possibilitar a descrição minuciosa das ações pedagógicas (discursivas e de transmissão), ajudam-nos a evidenciar como se produz uma aquisição seletiva.

\section{Referências}

ACOSTA, J. M. O currículo interpretado: o que as escolas, os professores e as professoras ensinam? In: SACRISTÁN, J.G. (Coord.). Saberes e incertezas sobre o currículo. Porto Alegre: Penso, 2013. p. 188-208.

ANDRÉ, M. E. D. A. Pesquisa sobre a escola e pesquisa no cotidiano escolar. ECCOSRevista Científica, São Paulo,vV. 10, n. especial, p. 133-145, 2008.

BERNSTEIN, B. A estruturação do discurso pedagógico: Classes, códigos e controle. Petrópolis: Vozes, 1996.

BONAFÉ, J. M.; RODRÍGUEZ, J. R. O currículo e o livro didático: uma dialética sempre 
aberta. In: SACRISTÁN, J.G. (Coord.). Saberes e incertezas sobre o currículo. Porto Alegre: Penso, 2013. p.209-225.

BRASIL. Lei de Diretrizes Operacionais Para a Educação Básica do Campo. Brasília, 2002.

CABRERA, R. C. Docência e desespero: Avaliação da aprendizagem na escola ciclada. Brasília: Liber Livro Editora, 2006.

CHIZZOTTI, A. A Pesquisa Qualitativa em Ciências Humanas e Sociais: Evolução e Desafios. Revista Portuguesa em Educação,vol.16, n.02, p.221-236, 2003

FONSECA, S. G. O trabalho do professor na sala de aula: relações entre sujeitos, saberes e práticas. Rev. Brasileira de Est. Pedagógicos, Brasília, v.91. n.228, p. 390-407, 2010.

GERALDI, C. M. G. Currículo em ação: buscando a compreensão do cotidiano da escola básica. Pro-posições, n.5, vol. 3, p. 11-132, 1994.

LUDKE, M.; ANDRÉ, M E. D. A. Pesquisa em educação: abordagem qualitativa. São Paulo: EPU, 1986.

MAINARDES, J. Reinterpretando os ciclos de aprendizagem. São Paulo: Cortez, 2007.

MOREIRA, A. F.; SILVA, T. T. da (Org.). Currículo, Cultura e sociedade. 7.ed. São Paulo: Cortez, 2002.

MORAIS, A. M. et al. Socialização primária e prática pedagógica. Lisboa: Fundação Caloustre Gulbenkian, 1993.

; NEVES, I. P. Processos de intervenção e análise em contextos pedagógicos. Educação, Sociedade e Culturas, Porto, n.19, p.49-87, 2003.

NEGRI, S. R. de. Um currículo democrático na contemporaneidade: desafios e possibilidades teóricas. Educação em Perspectiva, Viçosa, v.1, n.2, p. 274-292, 2010.

PICCOLI, L. Prática pedagógica nos processos de alfabetização e de letramento: análises a partir dos campos da sociologia e da linguagem. 2009. Tese (Doutorado em Educação). Faculdade de Educação, Universidade Federal do Rio Grande do Sul, Porto Alegre, 2009.

SACRISTÁN, J. G. O currículo uma reflexão sobre a prática. 3.ed. Porto Alegre: Artmed, 2000. 
Recebido em: 28/01/2015

Revisado em: 27/02/2016

Aprovado para publicação em: 19/04/2016

Publicado em: 30/04/2016 